\title{
How Does Slack Influence Inflation?
}

\author{
Richard Peach, Robert Rich, and Anna Cororaton
}

\begin{abstract}
Economists have long studied the relationship between resource utilization and inflation. Theory suggests that when firms use labor and capital very intensively, production costs tend to rise and firms have more scope to pass those cost increases along in the form of higher product prices. In contrast, when that level of intensity is relatively low - that is, when the economy is operating with slack - production costs tend to rise more slowly (or even fall) and firms have less scope for raising prices. Empirical evidence, however, has varied concerning the exact nature of the relationship between resource utilization and inflation. In this study, the authors reexamine this relationship by evaluating the presence of "threshold effects." They find that the level of intensity of resource utilization must be below or above certain critical values before it can help to forecast movements in inflation.
\end{abstract}

U nderstanding the role that resource utilization - a gauge of the balance between aggregate demand and supply in an economy-plays in the inflation process is an important issue, particularly at a time when the unemployment rate remains stubbornly high. Economic theory predicts that inflation will increase when an economy is operating above its potential — when firms are likely to be using labor and capital very intensively — and will slow when operating below its potential. And, in fact, this relationship is borne out by empirical analysis of post-World War II U.S. data up to the mid-1980s: When the unemployment rate was relatively low, the rate of inflation increased. Conversely, when the unemployment rate was relatively high, inflation slowed. Surprisingly, however, over the period from the mid-1980s through the mid-2000s, the relationship between the unemployment rate and the level of inflation proved very weak at best, leading some commentators to conclude that measures of resource utilization might no longer be useful predictors of future changes in the rate of inflation.

Other commentators, however, have viewed this mixed empirical evidence as support for the hypothesis that the level of resource utilization must exceed or fall below certain thresholds before it has a meaningful impact on inflation. In other words, the unemployment rate will help predict future inflation only when it is above or below critical values, as it occasionally was over the period from the end of World War II through the mid-1980s. By contrast, the unemployment rate will have little power to predict inflation during periods when movements of the unemployment rate are relatively muted - such as the period between the mid-1980s and the mid-2000s that economists call the "Great Moderation."

In this edition of Current Issues, we evaluate this hypothesis using a model that relates the rate of inflation to the unemployment gap - the difference between the actual unemployment rate and the non-accelerating inflation rate of unemployment, 
or NAIRU. As its name suggests, the NAIRU is that level of the unemployment rate at which there is no tendency for inflation to increase or decrease. We use this model to gauge the presence of thresholds beyond which the relationship between inflation and the unemployment gap becomes stronger in both economic and statistical terms. We also examine the model's ability to forecast "core" inflation-an inflation measure that excludes volatile food and energy prices-over the period from 2008 through the end of 2010 .

The results of our analysis indicate that the impact of the unemployment gap on inflation differs markedly within and outside the estimated thresholds, with economically and statistically significant effects associated with deviations of the unemployment rate from the NAIRU larger than 1.6 percentage points in absolute value. In addition, we find that the model-generated forecasts of inflation have generally tracked the slowing of core inflation over the 2008-10 period. We conclude that these results, taken together, provide general support for the notion that the unemployment gap must be below or above certain threshold values before it can help to predict movements in inflation and thereby serve as a useful guide for monetary policymakers.

\section{Background}

The inverse relationship between inflation and unemployment is the defining feature of the "Phillips curve," named for the New Zealand-born economist A. W. Phillips. In a 1958 study of U.K. economic data from 1861 to 1957, Phillips documented that nominal wages had grown faster during periods when the unemployment rate was low; when unemployment was high, wages had grown more slowly. Subsequent interpreters of Phillips' empirical findings saw the relationship between wage inflation and unemployment as a stable one that would allow analysts to predict how the inflation rate would change in response to particular movements in the unemployment rate.

Today, after fifty years of additional research, a modified version of the Phillips curve-the "expectations-augmented Phillips curve" - is a widely used tool for explaining and forecasting inflation. In this version, the rate of inflation is determined by a combination of inflation expectations, some measure of the overall state of resource utilization, and variables that capture supply shocks such as large, sharp changes in commodity prices. Commonly used measures of the state of resource utilization are the unemployment gap (defined earlier) and the output gap-actual GDP relative to the economy's maximum sustainable output, or "potential GDP."1 All else equal, the expectationsaugmented Phillips curve posits that conditions of slack in the economy-that is, "activity gap" measures indicating that output

\footnotetext{
${ }^{1}$ Potential GDP is that level of real output at which inflation would remain stable. The potential growth rate of real GDP is that at which the unemployment rate would remain unchanged.
}

Chart 1

\section{The Unemployment Gap and Core PCE Inflation: Time Series of the Data}

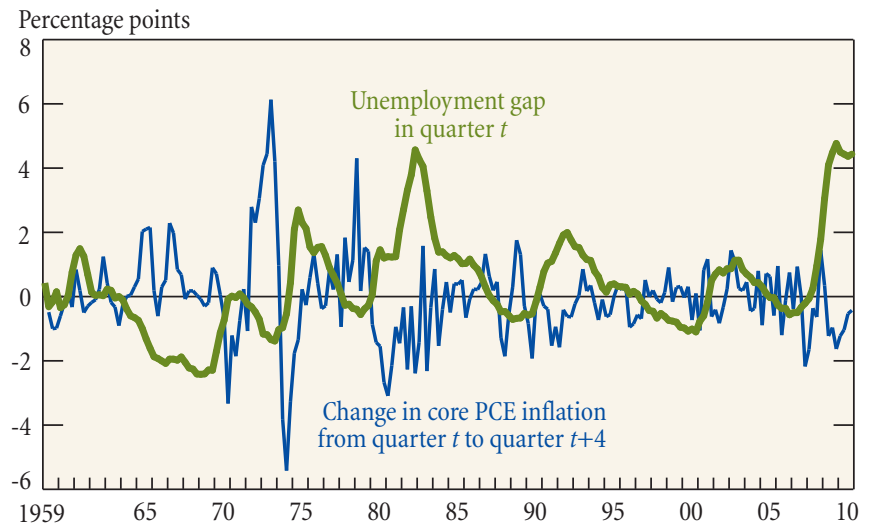

Sources: U.S. Bureau of Economic Analysis; U.S. Bureau of Labor Statistics; Congressional Budget Office.

Notes: The unemployment gap is the difference between the actual unemployment rate and the Congressional Budget Office's estimate of the non-accelerating inflation rate of unemployment (NAIRU). Core PCE inflation is the personal consumption expenditures deflator excluding food and energy.

and employment are below their potential levels—will lead to a decline in inflation and vice versa. ${ }^{2}$

The relationship between inflation and resource utilization over the last fifty years is shown in Chart 1. The chart presents a long time series of the four-quarter change in the growth rate of the core personal consumption expenditures (PCE) deflator, which excludes energy and food. ${ }^{3}$ Also plotted is the unemployment gap, measured as the difference between the actual unemployment rate and the estimate of the NAIRU produced by the Congressional Budget Office (CBO). Clearly visible are episodes in which the actual unemployment rate was above the NAIRU and inflation subsequently fell —as well as episodes in which the actual unemployment rate was below the NAIRU and inflation subsequently rose. Also evident, however, are periods in which the linkage between the variables appears to be rather weak.

\footnotetext{
${ }^{2}$ Going forward, we will refer to the expectations-augmented Phillips curve simply as the Phillips curve for ease of exposition.

${ }^{3}$ Letting $\pi_{t}$ denote the (annualized) growth rate in the core PCE deflator index from quarter $t-1$ to quarter $t$, the series is defined as $\pi_{t+4}-\pi_{t}$. The plot of the series in quarter $t$ depicts the value of $\left(\pi_{t+4}-\pi_{t}\right)$, with positive (negative) values representing an increase (decrease) in the level of inflation over the next year.

The PCE deflator, published by the U.S. Bureau of Economic Analysis, is the price index for all goods and services consumed by the household sector, regardless of who pays for those goods and services. It differs in scope from the more familiar consumer price index (CPI), which is a price index of goods and services that households pay for out of pocket. Like the core CPI, the core PCE deflator excludes food and energy. However, in the case of the PCE deflator, only food purchased for off-premises consumption is excluded, while food consumed "away from home" (at a restaurant) is included in the core measure.
} 
Chart 2

\section{The Unemployment Gap and Core PCE Inflation: Scatter-Plot of the Data}

Four-quarter change in core PCE inflation (percentage points)

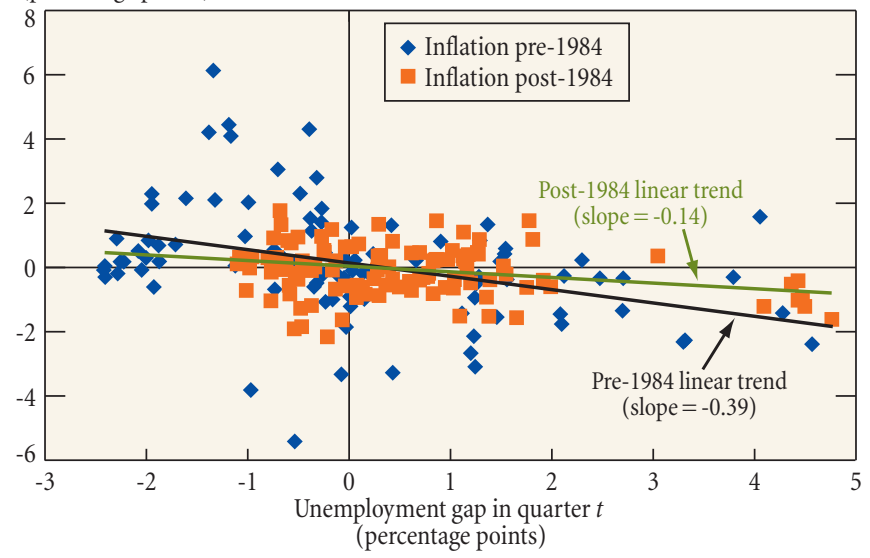

Sources: U.S. Bureau of Economic Analysis; U.S. Bureau of Labor Statistics; Congressional Budget Office.

Notes: The unemployment gap is the difference between the actual unemployment rate and the Congressional Budget Office's estimate of the non-accelerating inflation rate of unemployment (NAIRU). Core PCE inflation is the personal consumption expenditures deflator excluding food and energy.

Another way of viewing the relationship between resource utilization and inflation is presented in Chart 2, where the data in Chart 1 now appear in the form of a scatter-plot. Each dot represents an observation of the four-quarter change in core PCE deflator inflation and the corresponding value of the unemployment gap. The dots are color coded to separate pre-1984 (blue) and post-1984 (orange) observations. Note that the estimated slope of the pre-1984 observations is relatively steep, whereas the slope of the post-1984 observations is quite shallow. Specifically, the estimated slope over the post-1984 period is less than half the value observed over the pre-1984 period. The implication is that the relationship between the unemployment gap and inflation weakened in the post-1984 period.

The tenuous relationship between resource utilization and inflation over the post-1984 period could be interpreted as evidence of a long-term structural change in the economy that has made the Phillips curve relationship much less useful as a tool for forecasting inflation. Consider, however, that the period from the mid-1980s through the mid-2000s was unusually stable from a macroeconomic perspective. Output gaps and unemployment gaps were relatively small, and measured inflation expectations were relatively low and stable. Consequently, while the data indicate a weakened relationship between slack and inflation, this evidence could be an artifact of the "Great Moderation." Another look at Chart 2 offers some preliminary support for this claim: the pre-1984 period exhibits more extreme values of the unemployment gap than does the post-1984 period.
Earlier Views on the Predictive Power of the Phillips Curve

How useful is the Phillips curve in forecasting inflation over a one-to-two-year horizon? In a very influential article on this topic, Atkeson and Ohanian (2001) conduct a "horse race" between three alternative specifications of a Phillips curve model and a so-called naïve model that assumes that inflation over the next year will simply equal what it was over the preceding year. The authors conclude that for one-year-ahead forecasts of inflation over the 1984-99 period, "all three sets of NAIRU Phillips curvebased inflation forecasts have been no more accurate than the forecast from our naïve model.... We conclude that NAIRU Phillips curves are not useful for forecasting inflation" (p.3).

Other researchers have challenged the findings of Atkeson and Ohanian. Stock and Watson (2009) compare the accuracy of several different types of inflation-forecasting models, including "univariate models" - those that rely exclusively on one or more past values of inflation to predict inflation (the naïve model described above is a particular example of a univariate model). As the authors report, "one of our key findings is that the performance of Phillips curve forecasts is episodic: there are times, such as the late 1990s, when Phillips curve forecasts improved upon univariate forecasts, but there are other times (such as the mid-1990s) when a forecaster would have been better off using a univariate forecast" (p. 2). Moreover, they find that the times when a Phillips curve model outperforms a univariate forecast are those in which the output gap or unemployment gap is relatively large.

Liu and Rudebusch (2010) develop a statistical model in which changes in inflation in a given period depend on previous changes in inflation and the previous unemployment gap. They also consider a univariate model that includes only the previous changes in inflation. They estimate the two inflation models over a sample period from first-quarter 1984 to fourth-quarter 2007, and then generate out-of-sample forecasts for the period from firstquarter 2008 through third-quarter 2009. Judging the accuracy of the two models by a measure known as "root mean squared error (RMSE)" - the square root of the average squared difference between the predicted and the actual values of inflation - the authors find that the model with the unemployment gap has an RMSE that is only about 25 percent that of the univariate model. They conclude that the high level of the unemployment gap during 2008-09 contributed to the substantial decline in the inflation rate as predicted by the Phillips curve.

While the studies summarized here appear contradictory, it is possible to reconcile the results by arguing that the Phillips curve displays threshold effects. That is, the nature of the relationship between inflation and an activity variable such as the unemployment gap may change according to whether the gap lies above or below a particular value, or threshold. This view is consistent with Stock and Watson's finding that measures of economic activity do not help improve the accuracy of inflation forecasts in relatively 
Chart 3

\section{The Threshold Phillips Curve}

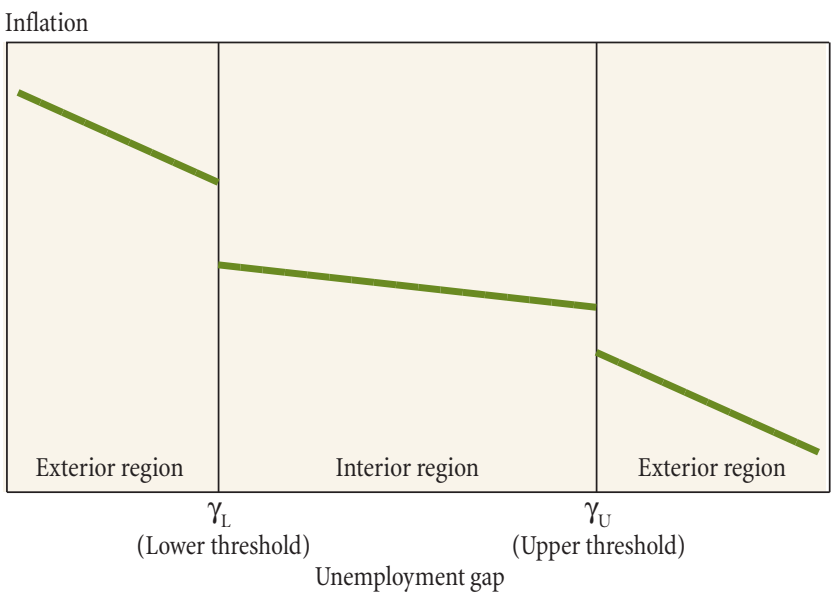

Notes: The chart shows the response of inflation to extreme movements in the unemployment gap (the exterior regions) and to more moderate movements in the gap (the interior region). The unemployment gap is the difference between the actual unemployment rate and the Congressional Budget Office's estimate of the non-accelerating inflation rate of unemployment (NAIRU).

tranquil periods, but do help to predict inflation in periods when the unemployment rate deviates markedly from NAIRU. The view can also accommodate the seemingly contrary results obtained by Atkeson and Ohanian, on the one hand, and Liu and Rudebusch, on the other. The authors' forecast exercises take place during very different times - a period of relative tranquility in the case of the first study and a large economic downturn in the case of the second.

The idea of a threshold relationship between activity measures and inflation was previously formalized by Barnes and Olivei (2003), who proposed a "piecewise" linear Phillips curve specification. In this type of relationship, depicted in Chart 3, inflation displays little response to movements in the unemployment gap that occur between a lower threshold $\left(\gamma_{L}\right)$ and upper threshold $\left(\gamma_{U}\right)$, but shows a more pronounced response to movements in the unemployment gap outside of this interval. While Barnes and Olivei found evidence to support their threshold Phillips curve specification, their analysis ended in 2002. Now, with the unemployment rate still quite high nearly two full years into the recovery, we believe it would be useful to reexamine the issue of a threshold relationship between inflation and economic slack with the addition of more current data.

\section{Price Inflation Phillips Curve Model}

Our specification of the Phillips curve model draws upon Gordon's (1990) "triangle" model of inflation with minor modifications. In the triangle model, there are three determinants of inflation: an inertial component, an activity gap measure, and a supply shock variable. Inertia refers to the tendency of inflation to deviate only gradually from its own past values owing to the slow adjustment of inflation expectations, proxied here by a weighted average of past inflation and a measure of long-run (ten-year) inflation expectations. ${ }^{4}$ Our activity gap variable-defined as the difference between the unemployment rate and the CBO estimate of the NAIRU - is meant to account for conditions of tightness or slack in the economy. ${ }^{5}$ The third determinant of inflation in the model is the supply shock variable. We use relative import price inflation, or the growth rate of import prices relative to the domestic inflation rate, as our supply shock variable. ${ }^{6}$ While one might argue that the exchange value of the dollar should be used instead, the fact that the linkage between the exchange rate and import prices varies substantially over time makes this measure less useful.

Our analysis involves several steps. First, we estimate a Phillips curve model in which the rate of inflation is determined by a combination of past inflation, inflation expectations, the unemployment gap, and relative import prices. In this "standard model," the impact of the unemployment gap on inflation does not change. We then estimate a second model in which we allow for the presence of threshold effects, meaning that there are values of the unemployment gap beyond which the effect on inflation differs from what it is when the gap is within those thresholds. The details of this exercise are provided in the accompanying box. Because equations (1) and (2) in the box have very different predictions for the role of activity gaps in the inflation process, it would seem that testing directly for the presence of threshold effects in the data would be a natural approach to evaluate the competing models. Unfortunately, testing for threshold effects is complex and the estimation of thresholds also involves uncertainty. ${ }^{7}$

Because of these difficulties, we rely on a less formal approach to assess the presence of threshold effects. Specifically, we examine if there is a marked difference in the estimated slopes of the Phillips curve with and without threshold effects and, in the threshold case, compare estimates for the interior and exterior regions of the curve. In addition, we examine whether the forecast profile of inflation from the threshold Phillips curve model is consistent with the recent path of inflation, given the observed paths of long-run inflation expectations, the unemployment gap, and import prices. While these exercises should not be viewed as a perfect substitute for more formal testing procedures, they are instructive and allow us to gain insights into the extent to which activity gaps are useful components of empirical models of inflation.

\footnotetext{
4 The inclusion of lagged, or past, inflation rates can be viewed either as capturing a backward-looking component of inflation expectations or as an additional source of inertia stemming from wage and price contracts in the economy.

${ }^{5}$ See U.S. Congressional Budget Office (2002) for a discussion of how this estimate of NAIRU is derived.

${ }^{6}$ Oil prices are included as a component in the import price series.

${ }^{7}$ See Hansen $(1996,2000)$ for a more detailed discussion.
} 


\section{The Threshold Phillips Curve Model}

To understand the threshold Phillips curve model, consider first the specification of the standard Phillips curve model used in our analysis:

$$
\pi_{t}=\sum_{i=1}^{3} \alpha_{i} \pi_{t-i}+\lambda \pi_{t-1}^{e}+\beta \tilde{u}_{t-1}+\chi z_{t-1}+\varepsilon_{t},
$$

where $\pi_{t}$ is (annualized) quarterly core PCE inflation, $\pi_{t-1}, \ldots, \pi_{t-3}$ are three lagged values of inflation, $\pi_{t-1}^{e}$ is the lagged value of long-run PCE inflation expectations, $\tilde{u}_{t-1}$ is the lagged value of the unemployment gap, $z_{t-1}$ is the lagged value of the supply shock variable, and $\varepsilon_{t}$ is an error term. The measure of long-run PCE inflation expectations is a hybrid of two different data series. For the period before fourth-quarter 1991, the measure of inflation expectations is taken from the Federal Reserve Board's FRB/US model. From fourth-quarter 1991 onward, the series is calculated as the ten-year-ahead consumer price index (CPI) inflation expectations series from the Survey of Professional Forecasters less 55 basis points to account for the historical difference between the two inflation series. The unemployment gap is measured as the difference between the unemployment rate and the Congressional Budget Office's estimate of the time-varying NAIRU $\left(\tilde{u}=u-u^{\text {NAIRU }}\right)$. Relative import price inflation is measured as the quarterly (annualized) growth rate of import prices less quarterly (annualized) core PCE inflation $\left(\pi^{I M P O R T}-\pi\right)$.

The threshold Phillips curve model provides a counterpart to the standard specification in equation (1) and is given by:

$$
\begin{aligned}
& \pi_{t}=\sum_{i=1}^{3} \alpha_{i} \pi_{t-i}+\lambda \pi_{t-1}^{e}+\beta_{I} \tilde{u}_{t-1}+\chi z_{t-1}+\varepsilon_{t}, \text { if } \gamma_{L} \leq \tilde{u}_{t-1} \leq \gamma_{U} \\
& \pi_{t}=\sum_{i=1}^{3} \alpha_{i} \pi_{t-i}+\lambda \pi_{t-1}^{e}+\beta_{E} \tilde{u}_{t-1}+\chi z_{t-1}+\varepsilon_{t}, \text { otherwise, }
\end{aligned}
$$

where the modification in equation (2) allows the trade-off between inflation and unemployment to depend on the level of the unemployment gap. In particular, we assume that the slope of the Phillips curve can change according to whether the unemployment gap lies between or outside the threshold values. If the unemployment gap is between the lower threshold $\left(\gamma_{L}\right)$ and the upper threshold $\left(\gamma_{U}\right)$, then the coefficient $\beta_{I}$ measures the slope of the Phillips curve in this interior region. By contrast, if the unemployment gap lies below the lower threshold or above the upper threshold, then the coefficient $\beta_{E}$ measures the slope of the Phillips curve in either exterior region. It is assumed that the other variables in the model do not produce threshold effects on the inflation process, although we allow relative import price inflation to have differential effects before and after 1984. ${ }^{\text {a }}$

\footnotetext{
a See Taylor (2000) and Hooker (2002) for further discussion. These studies document a decline since the mid-1980s in the impact of import prices and oil prices on the U.S. inflation process, and ascribe this development to the conduct of monetary policy and the establishment of a credible low-inflation environment.
}

Estimation of the threshold Phillips curve model is based on a grid search method. Specifically, a range of possible values is specified for the lower threshold and for the upper threshold, with a restriction on the range required to ensure that the number of observations in the interior and exterior regions is sufficient for model estimation. We allow the symmetric values of the lower (upper) threshold to range from -1.8 (1.8) to $-0.3(0.3)$, with the threshold values changing in increments of 0.01 within these ranges. ${ }^{\mathbf{b}}$ We also restrict the slope of the Phillips curve to be the same below the lower threshold and above the upper threshold. The estimation procedure then selects as the thresholds those combinations that result in the lowest sum of squared residuals.

\begin{tabular}{|c|c|c|}
\hline \multicolumn{3}{|c|}{ Phillips Curve Model Estimates } \\
\hline Parameter & $\begin{array}{l}\text { Standard Phillips } \\
\text { Curve Model }\end{array}$ & $\begin{array}{c}\text { Threshold } \\
\text { Phillips Curve Model }\end{array}$ \\
\hline$\alpha_{1}$ & $\begin{array}{l}0.440 * * * \\
(0.070)\end{array}$ & $\begin{array}{l}0.433^{* * *} \\
(0.070)\end{array}$ \\
\hline$\alpha_{2}$ & $\begin{array}{l}0.193 \text { ** } \\
(0.076)\end{array}$ & $\begin{array}{l}0.187^{\star *} \\
(0.076)\end{array}$ \\
\hline$\alpha_{3}$ & $\begin{array}{l}0.157^{* *} \\
(0.068)\end{array}$ & $\begin{array}{l}0.163^{* *} \\
(0.067)\end{array}$ \\
\hline$\lambda$ & $\begin{array}{l}0.211^{* * *} \\
(0.044)\end{array}$ & $\begin{array}{l}0.217^{\star * *} \\
(0.044)\end{array}$ \\
\hline$\beta$ & $\begin{array}{l}-0.144^{\star * *} \\
(0.045)\end{array}$ & - \\
\hline$\beta_{I}$ & - & $\begin{array}{l}-0.077 \\
(0.080)\end{array}$ \\
\hline$\beta_{E}$ & - & $\begin{array}{l}-0.173^{* * *} \\
(0.052)\end{array}$ \\
\hline$\chi_{\text {pre-84 }}$ & $\begin{array}{l}0.055^{\star * *} \\
(0.007)\end{array}$ & $\begin{array}{l}0.057^{* * *} \\
(0.007)\end{array}$ \\
\hline$\chi_{\text {post-84 }}$ & $\begin{array}{c}0.016 \\
(0.012)\end{array}$ & $\begin{array}{c}0.018 \\
(0.013)\end{array}$ \\
\hline$R^{2}$ & 0.90 & 0.90 \\
\hline
\end{tabular}

The estimation results for the standard and threshold Phillips curve models are presented below.

Note: Standard errors are reported in parentheses.

${ }_{* * *}$ Significant at the 1 percent level.

** Significant at the 5 percent level.

\footnotetext{
${ }^{\mathrm{b}}$ Once values are specified for $\gamma_{L}$ and $\gamma_{U}$, the threshold model in equation (2) can be estimated using the method of ordinary least squares.
} 
Chart 4

\section{The Unemployment Gap and Estimated Symmetric Thresholds}

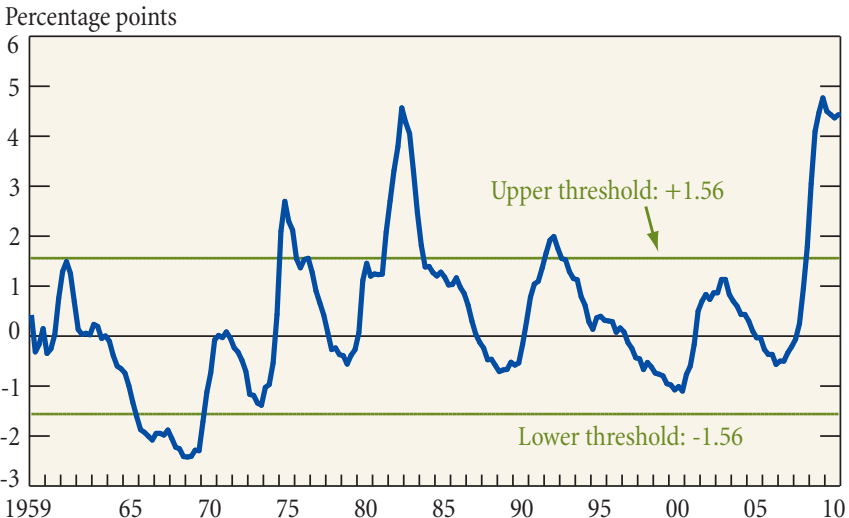

Sources: U.S. Bureau of Labor Statistics; Congressional Budget Office; authors' calculations.

Note: The unemployment gap is the difference between the actual unemployment rate and the Congressional Budget Office's estimate of the non-accelerating inflation rate of unemployment (NAIRU).

\section{Estimation Results}

The measure of inflation whose movements we seek to explain is the annualized quarterly percentage change in the core PCE deflator. The models for core PCE deflator inflation are estimated over the period from first-quarter 1961 through fourth-quarter 2007 to mitigate the influence of the Great Recession. The estimation results are presented in the table on page $5 .^{8}$ The regression results for the standard Phillips curve yield a statistically significant slope estimate of -0.14 . For the threshold Phillips curve model, two key results emerge. First, the estimated (absolute) value of the "threshold" unemployment gap is 1.56 percentage points. This figure is very close to the 1.5 percentage point figure identified by Stock and Watson (2009) as the threshold beyond which Phillips curve models provide forecast improvements over univariate models for inflation. ${ }^{9}$ As shown in Chart 4 , which presents a long time series of the unemployment gap, there have been relatively few episodes when it has exceeded these estimated thresholds. Four episodes, including the most recent, correspond to particularly severe recessions. Another, over the second half of the 1960s and into the early 1970s, corresponds to an extended period of intense resource utilization. The second key finding is that the slopes associated with the thresholds differ markedly in both economic

\footnotetext{
${ }^{8}$ To ensure that there is no long-run trade-off between inflation and unemployment, we undertake estimation of both models imposing the constraint that the coefficients on lagged inflation and the measure of inflation expectations sum to unity. This restriction was not rejected for either model.

${ }^{9}$ Barnes and Olivei (2003) allow for asymmetric thresholds and report estimates of -1.4 percent and 1.3 percent, respectively, for the lower and upper thresholds of their core PCE deflator Phillips curve model. When we allow for asymmetric thresholds, we obtain similar estimates of -1.3 percent and 1.1 percent. We elected to estimate the model with symmetric thresholds so that we could compare our findings with those of Stock and Watson (2009), who incorporate more recent data.
}

\section{Chart 5 \\ Phillips Curve Model Forecasts One-Quarter-Ahead Core PCE Inflation}

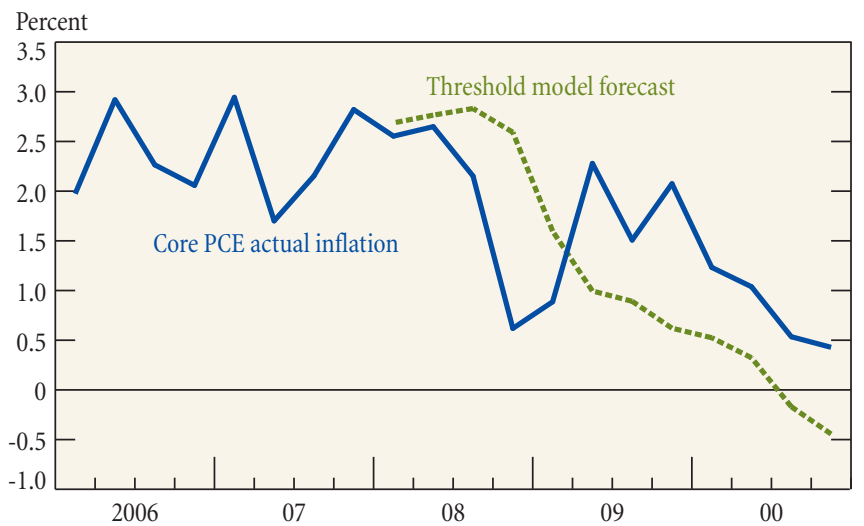

Sources: U.S. Bureau of Economic Analysis; authors' calculations.

Note: Core PCE inflation is the personal consumption expenditures deflator excluding food and energy.

and statistical significance. The estimated slope in the exterior region is -0.17 and is statistically significant, but the estimated slope declines to -0.07 and is not statistically significant when the unemployment gap lies in the interior region.

The initial results are consistent with the idea that the link from activity gaps to inflation is episodic — that is, the relationship is relevant only when conditions in the economy are either extremely slack or extremely tight. To examine the threshold Phillips curve model's usefulness as a forecasting tool, we conduct a dynamic simulation to judge how well the model's forecasts track the recent path of inflation. For the simulation, we retain the model's estimated parameters through the fourth quarter of 2007 to generate a one-quarter-ahead predicted value for first-quarter 2008 core PCE inflation. We then repeat the exercise for each subsequent period using the actual paths of long-run inflation expectations, the unemployment gap, and import prices as the explanatory variables. No actual values of inflation over the recent recession are used in the simulation. Rather, the simulation uses the post-2007 inflation forecasts from the model to forecast the subsequent values of inflation. In this manner, we generate a sequence of core PCE inflation forecasts for the period from first-quarter 2008 to fourth-quarter 2010.

Importantly, the one-quarter-ahead inflation forecasts produced by our dynamic simulation generally track the slowing observed in actual core PCE inflation since the first quarter of 2008 (Chart 5). ${ }^{10}$ To be sure, there have been some large deviations between the realized and forecasted values on a quarter-to quarter basis. For example, forecasted inflation appears to have lagged

\footnotetext{
${ }^{10}$ As a robustness check, we experimented with different choices for the thresholds but found that the slope estimates of the Phillips curve and the inflation forecast profiles did not materially change.
} 
the deceleration of actual inflation through the middle of secondquarter 2009, perhaps because of the role of inertia in the model. In addition, actual core inflation rose and then stabilized in 2009 while its forecasted value continued to decline. More recently, however, actual core inflation has moved significantly lower-as predicted by the model forecasts - with the model also pointing to some risk of deflation. It is important to note that the observed downward trend in actual and forecasted inflation occurs in spite of the fact that inflation expectations have remained quite steady: specifically, the inflation expectations series used in our model essentially held steady at 2 percent over the out-of-sample forecast exercise.

\section{Conclusion}

There has been considerable debate recently about the role of slack in the inflation process. Our study contributes to the debate by presenting evidence that the relationship between labor market slack and inflation is nonlinear-in particular, slack must exceed a threshold before exerting a statistically and economically significant effect on inflation. Importantly, our threshold model tracks the considerable slowing of core inflation that has occurred since the end of 2007 and can therefore serve as a useful guide in the monetary policy process.

Nevertheless, we recognize that some caution should be exercised in the interpretation of our results. For example, there is little theoretical work to explain the piecewise linear Phillips curve. In addition, there is a general absence of episodes in which low inflation and large unemployment gaps coincided in the sample period. Finally, the single-equation threshold Phillips curve model assumes that inflation expectations are not influenced by other variables in the model. It is likely, however, that inflation expectations are influenced by the amount of slack in the economy, which in turn could affect the estimates of the thresholds. While beyond the scope of this article, an interesting extension of our work would be the estimation of a multi-equation model that would treat inflation expectations as being influenced by variables such as the unemployment gap.

\section{We are grateful to Giovanni Olivei of the Federal Reserve Bank of Boston for his assistance and helpful comments.}

\section{References}

Atkeson, Andrew, and Lee E. Ohanian. 2001."Are Phillips Curves Useful for Forecasting Inflation?” Federal Reserve Bank of Minneapolis Quarterly Review 25, no. 1:2-11.

Barnes, Michelle, and Giovanni Olivei. 2003. "Inside and Outside Bounds: Threshold Estimates of the Phillips Curve." Federal Reserve Bank of Boston New England Economic Review, 3-18.

Gordon, Robert. 1990. "U.S. Inflation, Labor's Share, and the Natural Rate of Unemployment.” In Heinz Konig, ed., Economics of Wage Determination. Berlin: Springer-Verlag

Hansen, Bruce. 1996. "Inference When a Nuisance Parameter Is Not Identified under the Null Hypothesis." Econometrica 64, no. 2: 413-30.

_.2000. "Sample Splitting and Threshold Estimation." Econometrica 68, no. $3: 575-603$

Hooker, Mark A. 2002. "Are Oil Shocks Inflationary? Asymmetric and Nonlinear Specifications versus Changes in Regime." Journal of Money, Credit, and Banking 34, no. 2: 540-61.

Liu, Zheng, and Glenn Rudebusch. 2010. “Inflation: Mind the Gap.” Federal Reserve Bank of San Francisco Economic Letter, no. 2010-02.

Phillips, A. W. 1958. "The Relationship between Unemployment and the Rate of Change of Money Wages in the United Kingdom, 1861-1957." Economica 25, no. 100: 283-99.

Stock, James, and Mark Watson. 2009. "Phillips Curve Inflation Forecasts." In Understanding Inflation and the Implications for Monetary Policy: A Phillips Curve Retrospective. Proceedings of the Federal Reserve Bank of Boston's 2008 economic conference. Cambridge, Mass.: MIT Press.

Taylor, John B. 2000. "Low Inflation, Pass-thru, and the Pricing Power of Firms." European Economic Review 44, no. 7: 1389-1408.

U.S. Congressional Budget Office. 2002. The Effect of Changes in Labor Markets on the Natural Rate of Unemployment. April.

\section{ABOUT THE AUTHORS}

Richard Peach is a senior vice president, Robert Rich an assistant vice president, and Anna Cororaton an assistant economist in the Macroeconomic and Monetary Studies Function of the Federal Reserve Bank of New York.

Current Issues in Economics and Finance is published by the Research and Statistics Group of the Federal Reserve Bank of New York. Linda Goldberg and Erica L. Groshen are the editors.

Editorial Staff: Valerie LaPorte, Mike De Mott, Michelle Bailer, Karen Carter

Production: Carol Perlmutter, David Rosenberg, Jane Urry

Subscriptions to Current Issues are free. Send an e-mail to Research.Publications@ny.frb.org or write to the Publications Function, Federal Reserve Bank of New York, 33 Liberty Street, New York, N.Y. 10045-0001. Back issues of Current Issues are available at http://www.newyorkfed.org/research/current_issues/.

The views expressed in this article are those of the authors and do not necessarily reflect the position of the Federal Reserve Bank of New York or the Federal Reserve System. 